\title{
Effect of glutamine-enriched nutritional support on intestinal mucosal barrier function, MMP-2, MMP-9 and immune function in patients with advanced gastric cancer during perioperative chemotherapy
}

\author{
JUAN WANG ${ }^{1}$, YANFEN $\mathrm{LI}^{2}$ and YUANLING QI ${ }^{2}$ \\ Departments of ${ }^{1}$ Clinical Nutrition and ${ }^{2}$ Oncology, Weifang People's Hospital, Weifang, Shandong 261000, P.R. China
}

Received March 16, 2017; Accepted June 28, 2017

DOI: $10.3892 / \mathrm{ol} .2017 .6612$

\begin{abstract}
We studied the effects of glutamine-enriched nutritional support on intestinal mucosal barrier, matrix metalloproteinase (MMP)-2, MMP-9 and immune function during perioperative chemotherapy in patients with advanced gastric cancer. The study was conducted on 94 patients with advanced gastric cancer admitted from April 2015 to March 2016. They were randomly divided into observation and control groups, $\mathrm{n}=47$. Control group was given basic nutritional support whereas glutamine-enriched nutritional support was given to patients in observation group. High-performance liquid chromatography was used to measure lactulose and mannitol ratio in urine (L/M) and ELISA was used to measure D-lactate levels before chemotherapy and in the 1st, 2nd and 3rd cycle of chemotherapy. Immunoglobulin level was detected by immune turbidimetry assay, T lymphocyte subsets were determined by flow cytometry after 3 cycles of chemotherapy, MMP-2 and MMP-9 of patients were compared between the two groups. The serious adverse reactions incidence (grade and IV) of patients were observed. To evaluate the life quality of patients, QLQ-C30 was used after 6 months. The levels of L/M and D-lactate in both groups after the first cycle of chemotherapy were significantly higher than that before chemotherapy; they began to decline after the second or third cycle, but were still significantly higher than the levels before chemotherapy $(\mathrm{p}<0.05)$. On comparison, between the two groups after $1 \mathrm{st}$, 2nd, 3rd cycle after chemotherapy, L/M and D-lactate levels of patients in the observation group were significantly lower than in the control group $(\mathrm{p}<0.05)$. Incidence of serious adverse reactions (grades III and IV) in observation group was significantly lower than control group $(\mathrm{p}<0.05)$. At follow-up
\end{abstract}

Correspondence to: Dr Yuanling Qi, Department of Oncology, Weifang People's Hospital, 151 Guangwen Street, Kuiwen, Weifang, Shandong 261000, P.R. China

E-mail:pdj9m9@163.com

Key words: glutamine, advanced gastric cancer, perioperative chemotherapy, intestinal mucosal barrier function, MMP-2, MMP-9 of 6 months, living quality scores of patients in observation group were significantly higher than control group $(\mathrm{p}<0.05)$. Glutamine-enriched nutritional support can effectively protect the intestinal mucosal barrier function in patients with advanced gastric cancer in their perioperative chemotherapy, improve the level of MMP-2 and MMP-9 in patients with advanced gastric cancer, enhance their immune function, reduce the incidence of adverse reactions and improve their quality of life, which is of remarkable clinical application value.

\section{Introduction}

Gastric cancer is the 3rd most common malignant tumor in humans and is the foremost common tumor of the digestive tract (1). As the early signs and symptoms of the tumor mimic common gastric disorder, it often misses the stage of conservative treatment. By the time the tumor is diagnosed it is in advanced stage, even though surgical resection is the most effective treatment, the prognosis at late stage is not very promising (2). Patients with advanced gastric cancer are usually treated by radiotherapy combined with chemotherapy. The patients have varying degrees of malnutrition due to cancer pathology, this coupled with side effects of chemotherapy further aggravate their malnutrition. Malnutrition leads to decreased immunity, further causing damage to the intestinal tract and intestinal mucosal barrier. All this may result in patients unable to tolerate the side effects of chemotherapy and interrupt the treatment, which will affect the efficacy and survival rate of patients $(3,4)$. Glutamate helps to improve the body immunity of cancer patients, maintain the intestinal mucosal barrier and accelerate tissue repair (5). This study explored the clinical application of glutamate enriched diet in patients with advanced gastric cancer.

\section{Materials and methods}

General information. The study was carried out in 94 patients with advanced gastric cancer admitted during April 2015 to March 2016. The patients were randomly divided into observation and control groups, each group had 47 cases. This study was approved by the Ethics Committee of Weifang People's Hospital. Signed written informed consents were obtained from the patients. 
Table I. General information of two groups.

\begin{tabular}{|c|c|c|c|c|}
\hline Item & Observation $(n=47)$ & Control $(n=47)$ & $\mathrm{t} / \chi^{2}$ & P-value \\
\hline $\operatorname{Sex}(M / F)$ & $29 / 18$ & $30 / 17$ & 0.046 & 0.831 \\
\hline Age (years) & $40-70$ & $40-75$ & & \\
\hline Average age (years) & 58.36 & 59.85 & 0.898 & 0.372 \\
\hline \multicolumn{5}{|l|}{ Differentiation (n, \%) } \\
\hline Well-differentiated adenocarcinoma & $21(44.68)$ & $19(40.42)$ & 0.174 & 0.677 \\
\hline Moderately differentiated adenocarcinoma & $16(34.04)$ & $17(36.17)$ & 0.047 & 0.829 \\
\hline Poorly differentiated adenocarcinoma & $10(21.28)$ & $11(23.40)$ & 0.061 & 0.804 \\
\hline \multicolumn{5}{|l|}{ Tumor size $(\mathrm{cm})$} \\
\hline$<3$ & $8(17.02)$ & $9(19.15)$ & 0.072 & 0.789 \\
\hline $3-5$ & $23(48.94)$ & $25(53.19)$ & 0.384 & 0.536 \\
\hline$>5$ & $16(34.04)$ & $13(27.66)$ & 0.449 & 0.503 \\
\hline
\end{tabular}

M, male; F, female.

Inclusion criteria: i) Advanced gastric cancer diagnosed by endoscopic pathology or enhanced computed tomography (CT) or magnetic resonance imaging (MRI); ii) chemotherapy was performed, expected survival time $>3$ months; and iii) consent form signed.

Exclusion criteria: i) The largest diameter of the tumor $>10 \mathrm{~cm}$; and ii) combined with severe heart, liver, lung, kidney and other vital organs failure. There were no significant differences between the two groups ( $p>0.05)$ (Table I).

\section{Methods}

Chemotherapy. Both groups were treated with oral capecitabine (SFDA approval no. H20133361; Qilu Pharmaceutical Co., Ltd., Jinan, China) after meal for day 1 to 14 of the therapy, $1,000 \mathrm{mg} \cdot \mathrm{m}^{-2}$ bid; gemcitabine $\left(1,000 \mathrm{mg} \cdot \mathrm{m}^{-2}\right)$ (SFDA approval no. H20113286; Qilu Pharmaceutical Co., Ltd.) was given by intravenous infusion on day 1 and 8 of therapy for three cycles in treatment with one cycle of 21 days.

Nutritional support. Both groups of patients were given parenteral nutrition support, the whole nutrition mixture (including sugar, fat and glycolipid in the ratio of 6:4, protein, electrolyte and vitamins) was prepared as per the standard of $20 \mathrm{kcal} /(\mathrm{kg} \cdot$ day $)$. The observation group was given alanyl glutamine injection at dose of $0.4 \mathrm{~g} /(\mathrm{kg} \cdot$ day) (SFDA approval no. 708H03527; Cisen Pharmaceutical Co., Ltd., Jining, China) in addition to the nutrition mixture.

Detections of indices. Lactulose/mannitol ratio, urine of patients was collected before and after each cycle of chemotherapy for 3 cycles. Six hours prior to urine collection, patients were given oral lactulose (2 g) (SFDA approval no. 10220H873; Abbott Biologicals B.V, Abbott Park, IL, USA), mannitol (1 g) (SFDA approval no. H37021265; Huaren Pharmaceutical Co., Ltd., Shandong, China) in fasting state. Urine was treated with xylene, placed at $-20^{\circ} \mathrm{C}$; the sample centrifuged at $2,650 \mathrm{xg}$ for $5 \mathrm{~min}$, the supernatant was added to acetonitrile and the mixture was centrifuged at $1,050 \mathrm{x}$ g for $10 \mathrm{~min}$. Then the protein and ions were removed, the supernatant was taken and made into 1,000, 500, 200, 100 and $50 \mathrm{mg} / \mathrm{l}$ standard samples. High performance liquid chromatography (HPLC) differential detection method was used to detect concentration of lactulose and mannitol according to the standard curve, then the ratio of lactulose to mannitol (L/M) was calculated.

$D$-Lactate. Fasting peripheral venous blood $(5 \mathrm{ml})$ from both groups of patients was collected before and after each cycle after chemotherapy and, centrifuged at $850 \mathrm{x}$ g for $10 \mathrm{~min}$, placed at $-20^{\circ} \mathrm{C}$ for $2 \mathrm{~h}$. The level of D-lactate was determined by ELISA.

Matrix metalloproteinase (MMP)-2 and MMP-9. ELISA was used to measure levels of MMP-2 and MMP-9 after 3rd cycle of chemotherapy (kit was provided by Beijing Winter Song Boye Biotechnology Co., Ltd., Beijing, China). All procedures were operated strictly in accordance with the instructions, optical density (OD) was read at the wavelength of $450 \mathrm{~nm}$ using a microplate reader (Jiangsu Puyun Biotechnology Co., Ltd., Jiangsu, China).

After 3 cycles of treatment, 3-5 ml fasting venous blood of the two groups of patients were collected, the serum was isolated and extracted, single nuclear cell was separated using Ficoll separation, then rabbit monoclonal CD3 (dilution, 1:50; cat. no. 300406), rabbit monoclonal CD4 (dilution, 1:50; cat. no. 100405) and rabbit monoclonal CD8 antibody (dilution, 1:50; cat. no. 100706) purchased from BioLegend (San Diego, CA, USA) were added, incubated in the dark for $30 \mathrm{~min}$, detected by flow cytometry (BD Biosciences, Franklin Lakes, NJ, USA), the levels of $\mathrm{T}$ lymphocyte subsets $\mathrm{CD}^{+}, \mathrm{CD}^{+}$, $\mathrm{CD}^{+}$were detected, $\mathrm{CD} 4^{+} / \mathrm{CD}^{+}$was calculated; the levels of immunoglobulin $\operatorname{IgG}, \operatorname{IgA}$ and $\operatorname{IgM}$ in patients was measured using turbidimetric method (kit was provided by Weifang Guarantee Biotechnology Co., Ltd., Weifang, China), operated strictly according to the instructions, the levels of $\operatorname{IgG}, \operatorname{Ig}$ A and IgM in the sample were calculated by measuring the turbidity of the reaction liquid and comparing with the standard solution.

Evaluation criteria. Both groups were evaluated on lactulose/mannitol ratio, D-lactate levels, MMP-9, MMP-2, T lymphocyte subsets $\mathrm{CD}^{+}, \mathrm{CD}^{+}, \mathrm{CD}^{+}, \mathrm{CD}^{+} / \mathrm{CD}^{+}$and immunoglobulins ( $\operatorname{IgG}, \operatorname{Ig} \mathrm{A}$ and $\operatorname{IgM}$ ).

Incidence of serious adverse reactions (grades III and IV) was collected, including nausea and vomiting, oral mucositis, abdominal pain, diarrhea and thrombocytopenia. 
Table II. L/M of patients before and 1, 2 and 3 cycles after chemotherapy.

\begin{tabular}{lccccc}
\hline Groups & Cases & Before & First & Second & Third \\
\hline Observation & 47 & $0.41 \pm 0.12$ & $0.95 \pm 0.07$ & $0.73 \pm 0.14$ & $0.54 \pm 0.13$ \\
Control & 47 & $0.42 \pm 0.11$ & $0.99 \pm 0.08$ & $0.85 \pm 0.15$ & $0.76 \pm 0.14$ \\
t-test & & 0.421 & 2.580 & 4.009 & 7.895 \\
P-value & & 0.674 & $0.012^{\mathrm{a}}$ & $<0.001^{\mathrm{b}}$ & $<0.001^{\mathrm{b}}$ \\
\hline
\end{tabular}

${ }^{\mathrm{a}} \mathrm{p}<0.05,{ }^{\mathrm{b}} \mathrm{p}<0.01$.

Table III. D-Lactate of patients before and 1, 2 and 3 cycles after chemotherapy (mg/l).

\begin{tabular}{lccccc}
\hline Groups & Cases & Before & First & Second & Third \\
\hline Observation & 47 & $7.52 \pm 2.15$ & $14.36 \pm 3.28$ & $11.42 \pm 2.26$ & $9.63 \pm 2.14$ \\
Control & 47 & $7.63 \pm 2.36$ & $16.34 \pm 3.35$ & $13.49 \pm 2.42$ & $11.63 \pm 2.26$ \\
t-test & & 0.236 & 2.895 & 4.286 & 4.405 \\
P-value & & 0.814 & $0.005^{\mathrm{a}}$ & $<0.001^{\mathrm{a}}$ & $<0.001^{\mathrm{a}}$ \\
\hline
\end{tabular}

${ }^{\mathrm{a} C}$ Compared with observation group, $\mathrm{p}<0.01$.

Table IV. Immunological indicators (g/l).

\begin{tabular}{lcccc}
\hline Groups & Cases & $\operatorname{IgA}$ & $\operatorname{IgG}$ & $\operatorname{IgM}$ \\
\hline Observation & 47 & $2.01 \pm 0.44$ & $8.05 \pm 2.63$ & $1.88 \pm 0.26$ \\
Control & 47 & $1.69 \pm 0.35$ & $6.67 \pm 2.45$ & $1.31 \pm 0.47$ \\
t-test & & 3.902 & 2.632 & 7.275 \\
P-value & & $<0.001^{\mathrm{a}}$ & $0.010^{\mathrm{a}}$ & $<0.001^{\mathrm{a}}$ \\
\hline
\end{tabular}

${ }^{\mathrm{a} C}$ Compared with observation group, $\mathrm{p}<0.01$.

Table V. T lymphocyte subsets.

\begin{tabular}{lccccc}
\hline Groups & Cases & $\mathrm{CD}^{+}$ & $\mathrm{CD}^{+}$ & $\mathrm{CD}^{+}$ & $\mathrm{CD}^{+} / \mathrm{CD}^{+}$ \\
\hline Observation & 47 & $70.53 \pm 5.16$ & $40.53 \pm 5.26$ & $24.18 \pm 3.63$ & $1.69 \pm 0.57$ \\
Control & 47 & $65.48 \pm 5.02$ & $37.67 \pm 5.42$ & $26.45 \pm 3.62$ & $1.45 \pm 0.48$ \\
t-test & & 4.809 & 2.596 & 3.036 & 2.208 \\
P-value & & $<0.001^{\mathrm{b}}$ & $0.011^{\mathrm{b}}$ & $0.003^{\mathrm{b}}$ & $0.03^{\mathrm{a}}$ \\
\hline
\end{tabular}

Compared with observation group, ${ }^{\mathrm{a}} \mathrm{p}<0.05,{ }^{\mathrm{b}} \mathrm{p}<0.01$.

Quality of life core scale (QLQ-C30) was used to evaluate the quality of life of patients (6). Body function, role function, cognitive function, emotional function and social function were scored, the data were linear converted into standard points from 0 to 100 according to the range, the standard scores are correlated to the quality of life.

Statistical analysis. Data were processed using SPSS 19.0 (SPSS Inc., Chicago, IL, USA) statistical software. The measurement data were expressed as mean \pm standard deviation (SD), using t-test, enumerate data were expressed as rate, using $\chi^{2}$ test. $\mathrm{P}<0.05$ was considered to indicate a statistically significant difference.

\section{Results}

$\mathrm{L} / \mathrm{M}$ and D-lactate level after the first cycle of chemotherapy was significantly higher than before chemotherapy, the levels dropped in the 2nd and the 3rd cycle, but were still higher than pre-chemotherapy $(\mathrm{p}<0.05), \mathrm{L} / \mathrm{M}$ and $\mathrm{D}$-lactate level in the observation group was significantly lower than that of the control group at the 1st, 2nd and 3rd cycle after chemotherapy $(\mathrm{p}<0.05)$ (Tables II and III).

After three cycles of treatment, the immunological indicators of the two groups of patients were compared, immunoglobulins $\operatorname{IgA}, \operatorname{IgG}$ and $\operatorname{IgM}$ in the observation group was significantly higher than that of the control group, the difference was significant $(\mathrm{p}<0.05)($ Table IV).

After three cycles of treatment, $\mathrm{T}$ lymphocyte subsets were compared, the $\mathrm{CD}^{+}, \mathrm{CD}^{+}$and $\mathrm{CD} 4^{+} / \mathrm{CD}^{+}$levels in the observation group was higher than that of the control group, $\mathrm{CD}^{+}$level was lower than that of the control group, comparison between groups were significant $(\mathrm{p}<0.05)($ Table $\mathrm{V})$.

MMP-2 and TIMP-9 level in both groups, after 3 cycles of treatment, the levels of MMP-2 and MMP-9 in the two groups were $237.95 \pm 9.42$ and $937.95 \pm 59.48 \mathrm{pg} / \mathrm{ml}$, respectively. The levels of MMP-2 and MMP-9 in the control group were $290.34 \pm 59.48,987.76 \pm 59.48$, the observation group was significantly lower than the control group, the difference was statistically significant $(\mathrm{p}<0.05)$ (Table VI).

Adverse reactions in both groups of patients, during chemotherapy, the incidence of adverse reactions in the observation group was significantly lower than the control group $(\mathrm{p}<0.05)$ (Table VII).

After 6 months of follow-up, quality of life was compared, the score for the observation group in all dimensions was significantly higher than that of the control group, the difference was significant $(\mathrm{p}<0.05)$ (Table VIII).

\section{Discussion}

Epidemiological studies have shown that there is association of gastric cancer with variety of factors, including diet and environmental factors (salted food intake, fried, smoked and preserved food, hot diet, moldy food, overwork, water pollution) infection factors (Helicobacter pylori), host factors (host genetic instability) (7). The molecular mechanism is overexpression of vascular endothelial growth factor (VEGF) directly stimulating angiogenesis, therefore promoting tumor invasion, metastasis and recurrence. VEGF when combined to epidermal growth factor receptor (EGFR), activating EGFR through the autophosphorylation of EGFR, thus multiple signaling pathways are activated to promote tumor cell division and migration $(1,8)$.

Gastric cancer itself can lead to decreased gastrointestinal function, malnutrition, and decreased intestinal mucosal barrier function and immune function (9). The results of this study showed that L/M after the first cycle of chemotherapy was significantly higher than that before chemotherapy; L/M ratio began to decrease in the second and third cycle, but was 
Table VI. MMP-2 and TIMP-9 level (pg/ml).

MMP-2

TIMP-9

\begin{tabular}{lccccc}
\cline { 5 - 6 } Groups & Cases & Before & After & Before & After \\
\hline Observation & 47 & $314.56 \pm 12.96$ & $238.93 \pm 9.48$ & $1022.68 \pm 73.33$ & $937.95 \pm 59.48$ \\
Control & 47 & $313.78 \pm 11.67$ & $290.34 \pm 11.67$ & $1023.14 \pm 73.47$ & $987.764 \pm 73.4$ \\
t-test & & 0.307 & 25.270 & 0.030 & 3.959 \\
P-value & 0.760 & $<0.001^{\text {a }}$ & 0.976 & $<0.001^{\text {a }}$ \\
\hline
\end{tabular}

${ }^{\mathrm{a} C}$ Compared with observation group, $\mathrm{p}<0.01$. MMP, matrix metalloproteinase.

Table VII. Adverse reaction incidence (n, \%).

\begin{tabular}{|c|c|c|c|c|c|c|}
\hline Groups & Cases & $\begin{array}{l}\text { Nausea and } \\
\text { vomiting }\end{array}$ & $\begin{array}{c}\text { Oral } \\
\text { mucositis }\end{array}$ & Thrombocytopenia & $\begin{array}{c}\text { Abdominal pain } \\
\text { and diarrhea }\end{array}$ & Incidence \\
\hline Observation & 47 & $4(8.51)$ & $1(2.12)$ & $3(6.38)$ & $1(2.12)$ & $9(19.14)$ \\
\hline Control & 47 & $10(21.27)$ & $4(8.51)$ & $6(12.76)$ & $4(8.51)$ & $24(51.06)$ \\
\hline t-test & & & & & & 10.507 \\
\hline P-value & & & & & & $0.001^{\mathrm{a}}$ \\
\hline
\end{tabular}

${ }^{\mathrm{a} C}$ Compared with observation group, $\mathrm{p}<0.01$.

Table VIII. Quality of life.

\begin{tabular}{lcccccc}
\hline Group & Case & Body function & Role function & Recognition function & Emotional function & Social function \\
\hline Observation & 47 & $80.62 \pm 3.23$ & $81.73 \pm 1.24$ & $78.72 \pm 3.23$ & $70.73 \pm 3.24$ & $77.73 \pm 5.44$ \\
Control & 47 & $71.74 \pm 3.24$ & $74.65 \pm 1.38$ & $70.34 \pm 3.24$ & $64.65 \pm 3.38$ & $70.65 \pm 6.38$ \\
t-test & & 13.307 & 26.162 & 12.557 & 8.903 & 5.789 \\
P-value & $<0.001^{\text {a }}$ & $<0.001^{\text {a }}$ & $<0.001^{\text {a }}$ & $<0.001^{\text {a }}$ & $<0.001^{\text {a }}$ \\
\hline
\end{tabular}

${ }^{\mathrm{a} C}$ Compared with observation group, $\mathrm{p}<0.01$.

still higher than that before chemotherapy $(\mathrm{p}<0.05)$. The L/M of the observation group was significantly lower than that of the control group $(\mathrm{p}<0.05)$.

$\mathrm{L} / \mathrm{M}$ ratio increase indicates the increase of intestinal mucosal permeability, which is due to the damage to intestinal mucosal cells from chemotherapy causing intestinal mucosal atrophy, resulting in the increased intercellular gap between the cells (10). Glutamine, one of the essential amino acids, plays a role in maintaining the intestinal mucosal barrier, giving glutamine-enriched nutritional support can reduce intestinal damage from chemotherapy; glutamine regulates peroxisome proliferator-activated receptor $\gamma$ and nuclear factor- $\kappa \mathrm{B}(\mathrm{NF}-\kappa \mathrm{B})$ activity, therefore inhibiting apoptosis of intestinal mucosal cells, regulating the expression of tight junction proteins, protecting intestinal mucosal barrier function, with the passage of time, it can make L/M gradually decline (11). D-lactate is a metabolite of intestinal bacteria, when chemotherapy damages the intestinal mucosal barrier, abundant D-lactate is produced. With the increase of intestinal permeability, D-lactate goes into the blood circulation system, measuring D-lactate can reflect the degree of intestinal mucosal injury (12). D-lactate during chemotherapy in the observation group is lower than the control group, indicating that the degree of intestinal mucosal injury is significantly lower than that of control group, which may indicate that glutamate-enriched nutritional support plays an important role in the reduce of intestinal injury, the improvement and repair of gastrointestinal tissue, regulation of the microbial balance of intestinal microflora.

The immune response in patients with gastric cancer is mainly mediated by $\mathrm{T}$ cells, measuring the level of $\mathrm{T}$ cell subsets can be used as a reference indicator for chemotherapy efficacy (13). $\mathrm{CD}^{+}$is expressed by all mature $\mathrm{T}$ cell surface antigens and can assist in the identification of $\mathrm{T}$ cell antigen receptors. $\mathrm{CD}^{+}$is a $\mathrm{T}$ helper cell with immunoregulatory function; $\mathrm{CD}^{+}$is mainly a cytotoxic $\mathrm{T}$ cell that can lead to immune dysfunction $(14,15)$. Normally the humoral immunity is maintained at a low level, during chemotherapy period, with the damage of intestine mucosa, dislocation of bacteria and endotoxin, mild infection occur, when the infection is increased, immunoglobulin $\operatorname{IgG}, \operatorname{IgM}, \operatorname{Ig}$ A levels will rise in order to strengthen the resistance (16). It is proved in this study 
that after 3 cycles of chemotherapy, the levels of $\mathrm{CD}^{+}, \mathrm{CD}^{+}$ and $\mathrm{CD}^{+} / \mathrm{CD}^{+}$in the observation group is higher than the control group, the level of $\mathrm{CD}^{+}$is lower than the control group, IgG, IgM, IgA are significantly higher than the control group $(\mathrm{p}<0.05)$, which may be because the catabolism of the patients are always stronger than anabolism, acute phase protein is consumed in a large quantity, causing negative nitrogen balance in the metabolism (17). Glutamine, as a conditional essential amino acid, is consumed as an important nitrogen and free amino acid carrier and donor that can provide energy for the rapid proliferation of $\mathrm{T}$ cells. With glutamine-enriched nutritional support, glutamine deficiency caused by large consumption can be compensated, the number of $\mathrm{T}$ lymphocytes can be effectively improved, $\mathrm{CD}^{+}, \mathrm{CD}^{+}$and $\mathrm{CD}^{+} /$ $\mathrm{CD}^{+}$levels are enhanced, the immune function of patients is improved (18). Glutamine can promote the transformation of B lymphocytes and the synthesis and secretion of immunoglobulin, therefore maintaining $\operatorname{IgG}, \operatorname{IgM}, \operatorname{IgA}$ levels at a high level, effectively improving the immune function of patients (16).

MMP-2, and MMP-9 are a type of MMPs, and belong to the gelatinase, mainly involved in the metabolism of type IV collagen in the basement membrane. It is the main enzyme for degrading extracellular matrix (ECM), and can be secreted by macrophage, neutrophils, capillary endothelial cells and tumor cells (19), it is widely involved in the metastasis of colorectal cancer, breast cancer, gastric cancer and other types of tumors by degrading ECM (20), it can also induce VEGF and basic fibroblast growth factor, thereby promoting tumor neovascularization and accelerating the progression of gastric cancer. Related animal experiments have also indicated that the levels of MMP-2 and MMP-9 in intestinal mucosa was positively correlated with intestinal permeability (19). The results have shown that after 3 cycles of treatment, the level of MMP-2 and MMP-9 in both groups declined, and the levels of MMP-2 and MMP-9 in the observation group were significantly lower than those in the control group $(p<0.05)$, indicating that with the decline of MMP-2 and MMP-9 level, their degradation effect on the tight junction between mucosal cells are relieved, intestinal mucosal permeability is decreased, the degree of damage to the mucosal barrier function is relieved. By adding glutamine, the damage to the intestinal mucosa can be repaired, therefore chemotherapy tolerance of patients is enhanced, the incidences of loss of appetite, nausea, vomiting, mucositis are effectively reduced.

In conclusion, administration of glutamine-enriched nutritional support to advanced gastric cancer patients can not only protect the intestinal mucosal barrier function, but also improve the immune resistance of patients, relieve the adverse reactions of chemotherapy, therefore improving the compliance of patients with chemotherapy, it is worth clinical promotion and application.

\section{References}

1. Wang K, Yuen ST, Xu J, Lee SP, Yan HH, Shi ST, Siu HC, Deng S, Chu KM, Law S, et al: Whole-genome sequencing and comprehensive molecular profiling identify new driver mutations in gastric cancer. Nat Genet 46: 573-582, 2014.

2. Beamish AJ, Chan DS, Blake PA, Karran A and Lewis WG: Systematic review and meta-analysis of enhanced recovery programmes in gastric cancer surgery. Int J Surg 19 (Suppl 1): 46-54, 2015.
3. Tahara T, Okubo M, Shibata T, Kawamura T, Sumi K, Ishizuka T, Nagasaka M, Nakagawa Y, Arisawa T, Ohmiya N, et al: Association between common genetic variants in pre-microRNAs and prognosis of advanced gastric cancer treated with chemotherapy. Anticancer Res 34: 5199-5204, 2014

4. Ikeguchi M, Saito H, Miki Y and Kimura T: Effect of fucoidan dietary supplement on the chemotherapy treatment of patients with unresectable advanced gastric cancer. J Cancer Ther 6: 1020-1026, 2015.

5. Jiang Q: Effect of glutamine's nutrition support on the postoperative nutrition and immune function in malignant tumor of gynecology patients. Pak J Pharm Sci 27 (Suppl 4): 1023-1027, 2014.

6. Bedard G, Zeng L, Zhang L, Lauzon N, Holden L, Tsao M, Danjoux C, Barnes E, Sahgal A, Poon M, et al: Minimal important differences in the EORTC QLQ-C30 in patients with advanced cancer. Asia Pac J Clin Oncol 10: 109-117, 2014.

7. Keszei AP, Goldbohm RA, Schouten LJ, Jakszyn P and van den Brandt PA: Dietary $N$-nitroso compounds, endogenous nitrosation, and the risk of esophageal and gastric cancer subtypes in the Netherlands Cohort Study. Am J Clin Nutr 97: 135-146, 2013.

8. Cross AJ, Freedman ND, Ren J, Ward MH, Hollenbeck AR, Schatzkin A, Sinha R and Abnet CC: Meat consumption and risk of esophageal and gastric cancer in a large prospective study. Am J Gastroenterol 106: 432-442, 2011.

9. Tegels JJ, de Maat MF, Hulsewé KW, Hoofwijk AG and Stoot JH: Value of geriatric frailty and nutritional status assessment in predicting postoperative mortality in gastric cancer surgery. J Gastrointest Surg 18: 439-446, 2014.

10. Lu H, Liu H, Wang J, Shen J, Weng S, Han L, Sun T, Qian L, Wu M, Zhu S, et al: The chemokine CXCL9 exacerbates chemotherapy-induced acute intestinal damage through inhibition of mucosal restitution. J Cancer Res Clin Oncol 141: 983-992, 2015.

11. Xu XD, Sun YS, Shao QS, Hu JF, Qian ZY, Zhou YL and Ye ZY: Effect of early enteral nutrition supplemented with glutamine on postoperative intestinal mucosal barrier function in patients with gastric carcinoma. Zhonghua Wei Chang Wai Ke Za Zhi 14: 436-439, 2011 (In Chinese).

12. Uchida H, Kawai Y, Kinoshita H, Kitazawa H, Miura K, Shiiba K, Horii A, Kimura K, Taketomo N, Oda M, et al: Lactic acid bacteria (LAB) bind to human B- or H-antigens expressed on intestinal mucosa. Biosci Biotechnol Biochem 70: 3073-3076, 2006.

13. Khan IS, Mouchess ML, Zhu ML, Conley B, Fasano KJ, Hou Y, Fong L, Su MA and Anderson MS: Enhancement of an anti-tumor immune response by transient blockade of central T cell tolerance. J Exp Med 211: 761-768, 2014.

14. Hung MH, Chan KC, Liu YJ, Hsu HH, Chen KC, Cheng YJ and Chen JS: Nonintubated thoracoscopic lobectomy for lung cancer using epidural anesthesia and intercostal blockade: A retrospective cohort study of 238 cases. Medicine (Baltimore) 94: e727, 2015.

15. Kahveci K, Ornek D, Doger C, Aydin GB, Aksoy M, Emre C, Deveci A, Bozkurt M and Ozgun G: The effect of anesthesia type on stress hormone response: Comparison of general versus epidural anesthesia. Niger J Clin Pract 17: 523-527, 2014.

16. Wang DC, Wang $X$ and Chen C: Effects of anti-human T lymphocyte immune globulins in patients: New or old. J Cell Mol Med 20: 1796-1799, 2016.

17. Kuhn KS, Muscaritoli M, Wischmeyer P and Stehle P: Glutamine as indispensable nutrient in oncology: Experimental and clinical evidence. Eur J Nutr 49: 197-210, 2010.

18. Hu YM, Yeh CL, Pai MH, Lee WY and Yeh SL: Glutamine administration modulates lung $\gamma \delta \mathrm{T}$ lymphocyte expression in mice with polymicrobial sepsis. Shock 41: 115-122, 2014.

19. Jakubowska K, Pryczynicz A, Iwanowicz P, Niewiński A, Maciorkowska E, Hapanowicz J, Jagodzińska D, Kemona A and Guzińska-Ustymowicz K: Expressions of matrix metalloproteinases (MMP-2, MMP-7, and MMP-9) and their inhibitors (TIMP-1, TIMP-2) in inflammatory bowel diseases. Gastroenterol Res Pract 2016: 2456179, 2016.

20. Khan S, Shukla S, Sinha S, Lakra AD, Bora HK and Meeran SM: Centchroman suppresses breast cancer metastasis by reversing epithelial-mesenchymal transition via downregulation of HER2/ERK1/2/MMP-9 signaling. Int J Biochem Cell Biol 58: $1-16,2015$. 